\title{
Prototype Weigh-In-Motion Performance
}

\section{October 2006}

Prepared by

R. K. Abercrombie, Ph.D.

D. L. Beshears

L. M. Hively, Ph.D.

M. B. Scudiere, Ph.D.

F. T. Sheldon, Ph.D.

Oak Ridge National Laboratory

James L. Schmidhammer, Ph.D.

Jeff Vanvactor

University of Tennessee 


\section{DOCUMENT AVAILABILITY}

Reports produced after January 1, 1996, are generally available free via the U.S. Department of Energy (DOE) Information Bridge:

Web site: http://www.osti.gov/bridge

Reports produced before January 1, 1996, may be purchased by members of the public from the following source:

National Technical Information Service

5285 Port Royal Road

Springfield, VA 22161

Telephone: 703-605-6000 (1-800-553-6847)

TDD: 703-487-4639

Fax: 703-605-6900

E-Mail: info@ntis.fedworld.gov

Web site: http://www.ntis.gov/support/ordernowabout.htm

Reports are available to DOE employees, DOE contractors, Energy Technology Data Exchange (ETDE) representatives, and International Nuclear Information System (INIS) representatives from the following source:

Office of Scientific and Technical Information

P.O. Box 62

Oak Ridge, TN 37831

Telephone: 865-576-8401

Fax: 865-576-5728

E-mail: reports@adonis.osti.gov

Web site: http://www.osti.gov/contact.html

This report was prepared as an account of work sponsored by an agency of the United States Government. Neither the United States government nor any agency thereof, nor any of their employees, makes any warranty, express or implied, or assumes any legal liability or responsibility for the accuracy, completeness, or usefulness of any information, apparatus, product, or process disclosed, or represents that its use would not infringe privately owned rights. Reference herein to any specific commercial product, process, or service by trade name, trademark, manufacturer, or otherwise, does not necessarily constitute or imply its endorsement, recommendation, or favoring by the United States Government or any agency thereof. The views and opinions of authors expressed herein do not necessarily state or reflect those of the United States Government or any agency thereof. 
ORNL/TM-2005-164

PROTOTYPE WEIGH-IN-MOTION PERFORMANCE

R. K. Abercrombie, Ph.D.

D. L. Beshears

L. M. Hively, Ph.D.

M. B. Scudiere, Ph.D.

F. T. Sheldon, Ph.D.

Oak Ridge National Laboratory

James L. Schmidhammer, Ph.D. Jeff Vanvactor

University of Tennessee

Date Published: October 2006

\author{
Prepared by \\ OAK RIDGE NATIONAL LABORATORY \\ P.O. Box 2008 \\ Oak Ridge, Tennessee 37831-6285 \\ Managed by \\ UT-Battelle, LLC \\ for the \\ U.S. DEPARTMENT OF ENERGY \\ under contract DE-AC05-00OR22725
}





\section{TABLE OF CONTENTS}

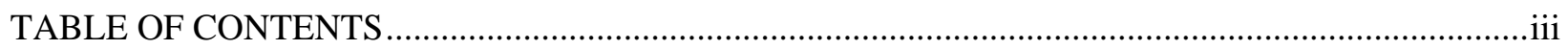

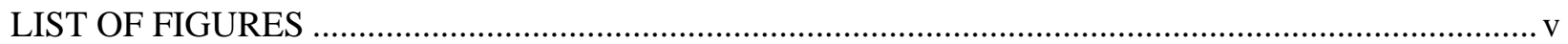

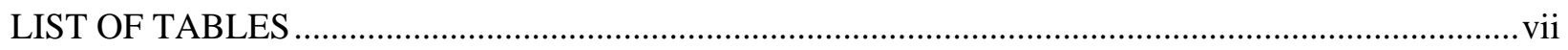

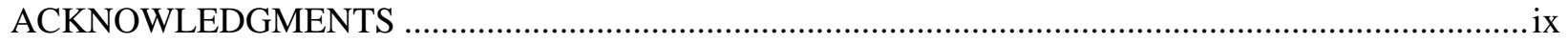

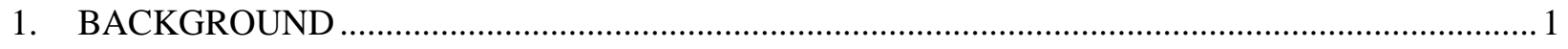

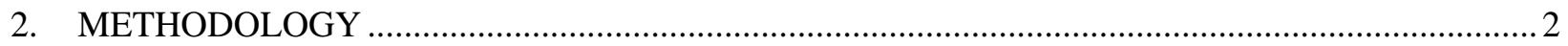

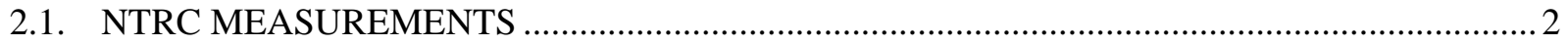

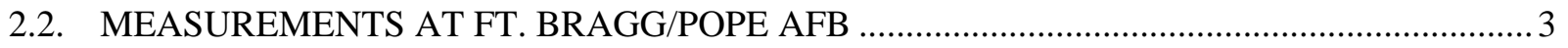

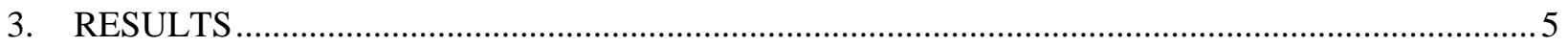

3.1. IN-GROUND STATIC SCALE MEASUREMENTS ................................................................ 5

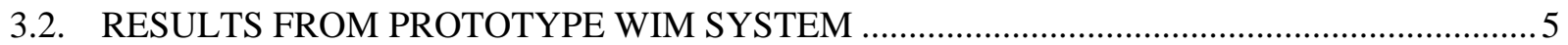

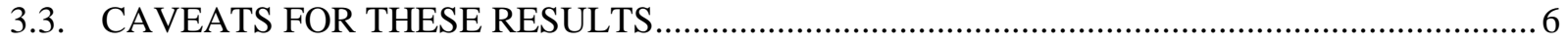

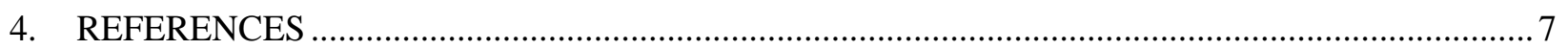

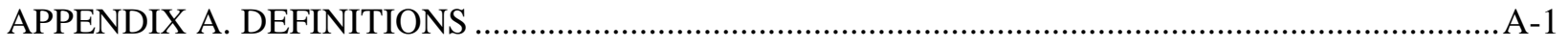

APPENDIX B. DETAILED RESULTS FROM VEHICLE TESTS AT NTRC .................................... B-1

APPENDIX C. DETAILED RESULTS FROM FT. BRAGG / POPE AFB ….......................................

APPENDIX D. WIM EQUIPMENT AND MEASUREMENT PROCEDURES .................................

APPENDIX E. RECOMMENDATIONS FOR FIELD USE OF WIM................................................ E-1 



\section{LIST OF FIGURES}

Figure

Page

Figure A-1. A histographic representation shows the accuracy and bias in a set of measurements.........A-3

Figure B-1. Percent Error in Axle Weights of Passenger and Light-Duty Vehicles on Static Scale....... B-4

Figure C-1. Percent Error versus Single-Axle Weight from the In-Ground Scale. ................................. C-5

Figure C-2. Percent Error versus Single-Axle Weight from the WIM dynamic mode............................ C-5

Figure D-1. WIM Gen II System Hardware Package. ..........................................................................

Figure D-2. WIM Gen II Cabling diagram with Host Box and Computer. .......................................... D-3

Figure D-3. WIM properly stacked for quick assembly. ……............................................................... D-4

Figure D-4. Placement of first two WIM measurement pads. ............................................................... D-4

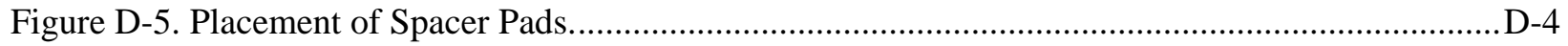

Figure D-6. Placement of next four weigh pads. .....................................................................................

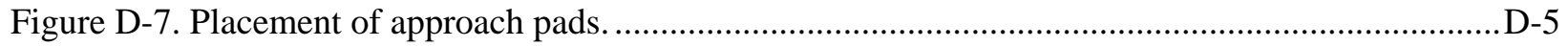

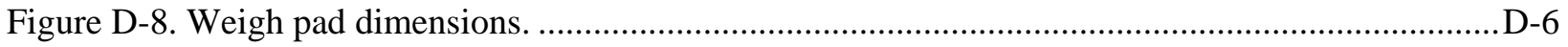





\section{LIST OF TABLES}

Table

Page

Table 1. Passenger and light-duty commercial vehicles measured at NTRC .3

Table 2. Time-Sequential Measurement Protocol........................................................................................

Table 3. Military vehicles measured at Ft. Bragg/Pope AFB ……........................................................... 3

Table 4. Percent Error for In-ground Static Scale Measurements Using Accepted Practices.......................5

Table 5. Error in Weight Measurements: WIM versus In-ground Static Scale .........................................5

Table A-1. Sample Data for Analysis of Total Vehicle Weight ............................................................. A-4

Table B-1. Percent Error from In-Ground Static Scale and WIM ......................................................... B-3

Table B-2. Percent Error in Weights from In-Ground Static Scale by Vehicle Type............................... B-3

Table C-1. Percent Error from In-Ground Static Scale and WIM ............................................................

Table C-2. Percent Error in Total Weight: WIM Stop-and-Go Mode versus In-ground Static Scale ...... C-4

Table C-3. Percent Error in Axle Weights: WIM Stop-and-Go Mode versus In-ground Scale ................ C-4 



\section{ACKNOWLEDGMENTS}

We are grateful for the contributions of the people who helped design, test, and evaluate the prototype Weighin-Motion Generation II System (WIM Gen II). We especially acknowledge the contributions of the following individuals:

Carolyn Brumbaugh, Christie McLaughlin and Robert McKay (Army Deputy Chief of Staff for Logistics, G4, Logistics Innovation Agency), who participated in several tests and were instrumental in arranging facilities and equipment for the tests;

Doug Flowers, Gerald Jensen, Mike Clever, and James Roth (Ft. Bragg, NC), who scheduled the testing and provided equipment and support personnel;

Julius Coats, who served as the military liaison for Oak Ridge National Laboratory (ORNL) and assisted in arranging facilities and equipment;

Gary Capps and Cliff White (ORNL), who were instrumental in designing and testing the WIM Gen II system;

Robert Schlicher and Dustin Leary (EigenSoft, Inc., under sub-contract to ORNL), who assisted in the software development for the WIM Gen II system and participated in much of the testing. 



\section{EXECUTIVE SUMMARY}

Oak Ridge National Laboratory (ORNL) has developed and patented methods to weigh slowly moving vehicles. We have used this technology to produce a portable weigh-in-motion system that is robust and accurate. This report documents the performance of the second-generation portable weigh-in-motion prototype (WIM Gen II). The results of three modes of weight determination are compared in this report: WIM Gen II dynamic mode, WIM Gen II stop-and-go mode, and static (parked) mode on in-ground, static scales. The WIM dynamic mode measures axle weights as the vehicle passes over the system at speeds of 3 to 7 miles per hour (1.3 to 3.1 meters/second). The WIM stop-and-go mode measures the weight of each axle of the vehicle as the axles are successively positioned on a side-by-side pair of WIM measurement pads. In both measurement modes the center of balance (CB) and the total weight are obtained by a straight-forward calculation from axle weights and axle spacings. The performance metric is measurement error (in percent), which is defined as $100 \mathrm{x}$ (sample standard deviation)/(average); see Appendix A for details. We have insufficient data to show that this metric is predictive.

This report details the results of weight measurements performed in May 2005 at two sites using different types of vehicles at each site. In addition to the weight measurements, the testing enabled refinements to the test methodology and facilitated an assessment of the influence of vehicle speed on the dynamic-mode measurements. The initial test at the National Transportation Research Center in Knoxville, TN, involved measurements of passenger and light-duty commercial vehicles. A subsequent test at the Arrival/Departure Airfield Control Group (A/DACG) facility in Ft. Bragg, NC, involved military vehicles with gross weights between 3,000 and 75,000 pounds (1,356 to 33,900 kilograms) with a 20,000-pound (9,040 kilograms) limit per axle. For each vehicle, four or more separate measurements were done using each weighing mode.

WIM dynamic, WIM stop-and-go, and static-mode scale measurements were compared for total vehicle weight and the weight of the individual axles. We made WIM dynamic mode measurements with three assemblages of weight-transducer pads to assess the performance with varying numbers $(2,4$, and 6$)$ of weigh pads. Percent error in the WIM dynamic mode was $0.51 \%, 0.37 \%$, and $0.37 \%$ for total vehicle weight and $0.77 \%, 0.50 \%$, and $0.47 \%$ for single-axle weight for the two-, four-, and six-pad systems, respectively. Errors in the WIM stop-and-go mode were $0.55 \%$ for total vehicle weight and $0.62 \%$ for single-axle weights. Inground scales weighed these vehicles with an error of $0.04 \%$ (within Army specifications) for total vehicle weight, and an error of $0.86 \%$ for single-axle weight. These results show that (1) the WIM error in single-axle weight was less than that obtained from in-ground static scales; (2) the WIM system eliminates timeconsuming manual procedures, human errors, and safety concerns; and (3) measurement error for the WIM prototype was less than $1 \%$ (within Army requirements for this project).

All the tests were performed on smooth, dry, level, concrete surfaces. Tests under non-ideal surface conditions are needed (e.g., rough but level, sun-baked asphalt, wet pavement), and future work will test WIM performance under these conditions. However, we expect the performance will be as good as, if not better than, the present WIM performance. We recommend the WIM stop-and-go mode under non-ideal surface conditions. We anticipate no performance degradation, assuming no subsurface deformation occurs.

We anticipate a phased approach to WIM deployment on the basis of these results in the context of military operations [1-3]. Specifically, we expect three successively more difficult operational scenarios during the continued testing and evaluation phase of the WIM system. These scenarios will define the functionality, procedures and standards necessary in the following contexts:

- Improved Power Projection Platform;

- Semi-austere in-theater Outside Continental United States (OCONUS);

- Austere.

A user's manual for the WIM system [1-2] was developed in conjunction with these tests. 



\section{BACKGROUND}

Rapid world-wide deployments are essential to the mission of the US Department of Defense (DoD). Such deployments require transport of personnel and materiel by road, rail, sea, or air. Stable air transport in particular requires determination of the vehicle's weight and CB. The process for load determination includes:

- $\quad$ Staging and identifying vehicles;

- Determining individual (single) axle weights and spacings;

- Calculating total vehicle weight and CB;

- Marking each vehicle with its total vehicle weight, axle weights, and CB;

- Accumulating vehicle data for a group of vehicles;

- Entering the data into a database for use by various military planning and visibility systems.

Present tools for vehicle total weight and CB include: portable-single-wheel- or in-ground-static scales for axle weights, tape measures for axle spacings, and clipboards and calculators. The current procedure for vehicle weight and $\mathrm{CB}$ is:

- Weigh the first axle and manually record the result;

- Weigh the first and second axle together and manually record the result;

- Subtract the first-axle weight from the axle-one-and-two weight to obtain the axle-two weight;

- Repeat this process until the weight of each axle is determined;

- Measure the distance from the front of the vehicle to each of the axles via a tape measure;

- Calculate CB with the above acquired information. (See Appendix A.)

This manual process for weighing and measuring vehicles (and palletized cargo) is labor-intensive, timeconsuming, and prone to human errors that cause significant safety hazards. Moreover, the lack of a standardized, joint-service airlift-weighing system creates redundant requirements at the cost of scarce time and resources.

Oak Ridge National Laboratory (ORNL) has developed and patented weigh-in-motion (WIM) technology [418] that provides a better approach. The Army Logistics Innovation Agency (LIA) and ORNL compared WIM measurements to the present approach (as described above) at Ft. Bragg/Pope Air Force Base in May 2003. The demonstration occurred under good working conditions with skilled Army personnel and showed errors resulting from manual data entry/calculation in $9 \%$ and $13 \%$ of the data taken from the in-ground and single-wheel scales, respectively. However, the initial WIM system did not meet the military requirement for $1.0 \%$ (or better) error in weight. Subsequently, LTA and ORNL have been developing a more capable WIM system. The present report describes performance of this improved WIM system, which was developed by ORNL as a prototype and subsequently specified to a commercial company for a limited (first article) production run. 


\section{METHODOLOGY}

This work assessed WIM performance via three measurement methods for individual (single) axle weights and for total vehicle weight: (1) current military weighing techniques via in-ground static scales by military personnel, (2) WIM dynamic mode as the vehicle moves over the scales, and (3) WIM stop-and-go mode on an axle-by-axle basis. In some instances, vehicle weight was altered by loading the vehicle with additional ballast. This report compares the performance of the WIM prototype system to the average performance of two static, in-ground scales at:

- National Transportation Research Center (NTRC), Knoxville, TN (May 10-12, 2005), using passenger and light-duty commercial vehicles with the prototype WIM Gen II system (details in Appendix B).

- Ft. Bragg/Pope AFB, NC (May 23-27, 2005), using military vehicles with a wide range of gross vehicle and axle weights with the prototype WIM Gen II system (details in Appendix C).

In the Scales section of the National Institute of Standards and Technology Handbook 44, user requirement UR.3.3 [19] stipulates that either the total vehicle must be weighed as a unit (single draft) or the individual elements (axles) must be weighed simultaneously.

UR.3.3. Single-Draft Vehicle Weighing. - A vehicle or a coupled vehicle combination shall be commercially weighed on a vehicle scale only as a single draft. That is, the total weight of such a vehicle or combination shall not be determined by adding together the results obtained separately and not [by] simultaneously weighing each end of such vehicle or individual elements of such coupled combination. However:

(a) the weight of a coupled combination may be determined by uncoupling the various elements (tractor, semi-trailer, trailer), weighing each unit separately as a single draft, and adding together the results, or

(b) the weight of a vehicle or coupled vehicle combination may be determined by adding together the weights obtained while all individual elements are resting simultaneously on more than one scale platform.

Simultaneous measurement of all axle weights eliminates the variations that are unavoidably present during sequential measurements of individual axle weights. These heightened measurement variations arise from nonlinear slip-stick behavior in the vehicle suspension that shifts weight from one axle to another as the vehicle moves onto the scale and then stops. All measurements in the WIM dynamic mode were obtained in accord with this NIST standard.

\subsection{NTRC MEASUREMENTS}

An evaluation of the first WIM prototype system was conducted at the NTRC using passenger and light-duty vehicles. The WIM prototype used off-the-shelf weight transducer pads that had been enhanced with the addition of electronics hardware and software designed, developed, and fabricated at ORNL. These tests were used to develop and verify a methodology for evaluation of the WIM first-article system. Table 1 lists the vehicles that were measured at the NTRC and Appendix B provides detailed results.

Each vehicle in Table 1 was weighed at least four times on an in-ground static scale. Each measurement included individual axle weights and total vehicle weight. The individual (single) axle weight was determined manually on the in-ground static scale using the procedure in Section 2 of this report. The total vehicle weight was determined by parking the entire vehicle on the in-ground static scale and manually recording its total weight. Each vehicle configuration in Table 1 was weighed under the same time-sequential protocol (Table 2). 
Table 1. Passenger and light-duty commercial vehicles measured at NTRC

\begin{tabular}{|l|c|c|}
\hline Vehicle & \# Axles & $\begin{array}{l}\text { Estimated } \\
\text { Weight (pounds) }\end{array}$ \\
\hline Chevy S10 & 2 & 3,200 \\
\hline Chevy S10 with load & 2 & 3,810 \\
\hline Dodge Caravan & 2 & 4,400 \\
\hline Ford F-250 & 2 & 6,810 \\
\hline Ford F-250 with load & 2 & 7,690 \\
\hline H2 Hummer & 2 & 6,850 \\
\hline H2 Hummer with load & 2 & 8,250 \\
\hline H2 Hummer with trailer & 3 & 9,015 \\
\hline
\end{tabular}

Table 2. Time-sequential measurement protocol

\begin{tabular}{|l|l|}
\hline Measurement Method & Number of independent measurements \\
\hline In-ground static scale (using the protocol in Section 3.1) & 2 , or sometimes 4 if time permitted \\
\hline WIM stop-and-go mode on a randomly chosen 2 pads & 2 \\
\hline WIM dynamic mode for 2-, 4-, and 6-pad combinations & $\begin{array}{l}5 \text { in one direction at }<7 \mathrm{MPH} \\
5 \text { in opposite direction at }<7 \mathrm{MPH} \\
5 \text { in one direction at 7-10 MPH } \\
5 \text { in opposite direction at 7-10 MPH }\end{array}$ \\
\hline WIM stop-and-go mode on the same randomly chosen 2 pads & 2 \\
\hline In-ground static scale & 2 , or sometimes 4 if time permitted \\
\hline
\end{tabular}

\subsection{MEASUREMENTS AT FT. BRAGG/POPE AFB}

A/DACG personnel at Ft. Bragg used two Metler-Toledo in-ground static scales for single-axle weight and total vehicle weight, as described in Section 3.1. These facilities and procedures are representative of military practice. Tests used military vehicles that are commonly out-loaded by the A/DACG: High Mobility Multipurpose Wheeled Vehicle (HMMWV), 2.5-Ton Light Medium Tactical Vehicle (LMTV), Heavy Expanded Mobility Tactical Truck (HEMTT), Pallet Loading System (PLS), and a trailer. These five vehicles were weighed in seven configurations, as shown in Table 3. Each configuration was weighed at least four times via the in-ground static scales, with the average of these weights shown in the Table 3.

Table 3. Military vehicles measured at Ft. Bragg/Pope AFB

\begin{tabular}{|l|c|c|}
\hline Vehicle & Number of axles & $\begin{array}{l}\text { Estimated } \\
\text { Weight (pounds) }\end{array}$ \\
\hline HMMWV & 2 & 5,677 \\
\hline HMMWV with trailer & 3 & 10,179 \\
\hline 2.5-Ton LMTV & 2 & 18,097 \\
\hline 2.5-Ton LMTV loaded & 2 & 22,620 \\
\hline HEMTT & 4 & 37,466 \\
\hline HEMTT loaded & 4 & 46,396 \\
\hline PLS & 5 & 51,497 \\
\hline
\end{tabular}


The WIM in stop-and-go mode measures axle weights, total vehicle weight, and center of balance as follows:

- Drive the first axle onto the first pair of WIM pads and obtain the axle-1 weight;

- Drive the second axle onto the first pair of WIM pads and obtain the axle-2 weight;

- Repeat the previous two steps to weigh all additional axles;

- Obtain the total weight automatically (sum of individual axle weights) after the last axle is weighed;

- Obtain the axle spacings automatically from the Unit Deployment List, or enter them manually;

- Determine the CB automatically.

Dynamic-mode WIM operation involves driving the vehicle over the measurement pads at a speed between 3 and 7 miles per hour (1.3 to 3.1 meters per second). The WIM system determines wheel weights, axle weights, total vehicle weight, and CB. The system performs these measurements automatically without manual intervention. The prototype WIM system was configured with three sets (A, B, and C) of two measurement pads. Data were analyzed for seven distinct pad combinations: three 2-pad systems (A, B, C), three 4-pad systems (AB, AC, BC), and one 6-pad system (ABC) for each measurement. Analysis of these combinations provides an estimate of measurement percent error (precision) in comparison with in-ground scale measurements. (See Appendix D for more details about the WIM measurement procedure and system hardware and software.) 


\section{RESULTS}

This section summarizes measurement results from tests at the NTRC (WIM prototype for passenger and light-duty commercial vehicles) and Ft. Bragg (WIM prototype for military vehicles). The WIM results were obtained in:

- Dynamic mode for a 2-, 4-, and 6-pad combinations to determine total weight, axle weights, and CB;

- Stop-and-go mode for one 2-pad set to determine total and individual axle weights.

The WIM system in stop-and-go mode obtains axle spacings from the Unit Deployment List (UDL) to enable a calculation of the vehicle CB. We compare WIM results to in-ground scale measurements of axle weights and total weight. Axle spacing was not measured by the in-ground scale, and thus a corresponding CB was unavailable.

\subsection{IN-GROUND STATIC SCALE MEASUREMENTS}

Single-axle weights and total weight were measured via static in-ground scales at the respective facilities. Table 4 summarizes the results from the two tests as a baseline for comparison to WIM performance. The right-most column in Table 4 shows an average of the two tests (sum of the errors, divided by two), which is appropriate because all of the in-ground-scale measurements use similar equipment and procedures. Table 4 shows an average error in total weight of $0.04 \%$, which satisfies the legal trade requirement of no more than $0.10 \%$. Individual axle weights are much less precise, with an average error of $0.86 \%$, which is typical of static measurements of axle weights due to the previously mentioned slip-stick suspension issues.

Table 4. Percent Error for In-ground Static Scale measurements using accepted practices

\begin{tabular}{|l|c|c|c|}
\hline $\begin{array}{l}\text { Weight } \\
\text { Measurement }\end{array}$ & NTRC & Ft. Bragg & Average \\
\hline Total Vehicle & 0.01 & 0.07 & 0.04 \\
\hline Single-Axle & 0.25 & 1.47 & 0.86 \\
\hline
\end{tabular}

\subsection{RESULTS FROM PROTOTYPE WIM SYSTEM}

Table 5 shows results from the WIM prototype. The weight-measurement mode was selected by the user. In WIM stop-and-go mode, the axle spacings for CB determination can be obtained from the UDL or they can be measured and then entered manually. WIM errors in total and axle weight satisfy the Army requirement in the stop-and-go mode and in the 4- and 6-pad dynamic modes; the error obtained using the 2-pad configuration in dynamic is not sufficiently low to definitively state that it is less than the $1 \%$ or better requirement.

Table 5. Error in weight measurements: WIM versus In-ground Static Scale

\begin{tabular}{|l|c|c|c|c|c|}
\hline \multirow{2}{*}{ Measurement } & \multirow{2}{*}{$\begin{array}{c}\text { In-Ground } \\
\text { Static Scale }\end{array}$} & \multicolumn{4}{|c|}{ Mode of WIM Prototype } \\
\cline { 3 - 6 } & & 2-pad Dynamic & 4-pad Dynamic & 6-pad Dynamic & Stop-and-Go \\
\hline Total Vehicle Weight & $0.04 \%$ & $0.51 \%$ & $0.37 \%$ & $0.37 \%$ & $0.55 \%$ \\
\hline Single-Axle Weight & $0.86 \%$ & $0.77 \%$ & $0.50 \%$ & $0.47 \%$ & $0.62 \%$ \\
\hline Center of Balance & \multirow{2}{*}{ NA } & $\begin{array}{c}1.57 \% \\
(1.57 \text { inches })\end{array}$ & $\begin{array}{c}2.31 \% \\
(2.04 \text { inches })\end{array}$ & $\begin{array}{c}0.50 \% \\
(0.44 \text { inches })\end{array}$ & $\begin{array}{c}0.40 \% \\
(0.34 \text { inches })\end{array}$ \\
\hline
\end{tabular}

All of these tests were performed on smooth, level, concrete surfaces. Future work should evaluate the WIM system under non-ideal surface conditions, which we expect to degrade measurements in the WIM dynamic 
mode. We currently suggest WIM operation in the stop-and-go mode under non-ideal surface conditions, for which we anticipate no degradation in measurement error. Appendix E gives recommendations for WIM use.

\subsection{CAVEATS FOR THESE RESULTS}

WIM weight measurements have inaccuracies that arise from vehicle oscillations. These vibrations occur, because a vehicle is (i) a set of coupled masses (e.g., cab, load, wheels) with (ii) interconnecting springs (e.g., cab-load coupling, wheel suspensions) that are (iii) damped by slip-stick friction and are (iv) excited by various external forces (e.g., uneven terrain, steering changes, acceleration, wind, load shifts in liquids, engine variation). The oscillations are a chaotic combination of rocking (e.g., side-to-side and front-to-back), bouncing (e.g., up-and-down), and twisting about each coupling point. The dominant frequency is in the range of 2.5 to $4 \mathrm{~Hz}$, and is dependent on the state of the suspension and the load. Accurate weight measurements require minimization of this excitation amplitude in both the static and dynamic WIM modes. The chaotic nature of these dynamics results in a different final state each time that the vehicle stops. The resultant redistribution of static weight among the tires causes variability in single-axle weight via the WIM stop-and-go mode. WIM dynamic-mode weight measurements also experience continuous chaotic variability from these oscillations, which the present system attempts to reduce by a combination of: (1) a smooth, flat, level approach, weighing, and exit; (2) driving at a constant speed in a straight line; (3) acquiring several single-axle weight measurements as the vehicle crosses multiple weigh pads; and (4) having the vehicle in motion to reduce the slip-stick friction. An important topic for future work is further reduction in WIM measurement error, which is dominated by these vehicle dynamics, rather than by the accuracy of the weigh pads. 


\section{REFERENCES}

[1] Oak Ridge National Laboratory, 2006, "Weigh-in-Motion, Cube Measurement, and Marking User Manual," This document is available from the WIM Share Point to registered users at https://share.ornl.gov/orgs/ioc/wim/ (registration for users can be requested by contacts listed at http://www.ioc.ornl.gov/.

[2] Twitero Website at DPMO for User Manual

Version 0.8.1 of User Training Outline and User Manual on FPIC Mobility Officer page/Automation List: https://fpic.eustis.army.mil/FPIC_Section/FPIC_Mobility_Officer.asp

Both documents are available on FPIC homepage in the "What's New" area, as updates. https://fpic.eustis.army.mil/FPIC_Section/FPIC_Home.asp

Links to ORNL WIM website and WIM videos are in place on the Mobility Officer page.

[3] R.K. Abercrombie, F.T. Sheldon, R.B. Schlicher and K.M. Daley, "Development of the Joint WeighIn-Motion (WIM) and Measurement Reach Back Capability - The Configuration and Data Management Tool,” SOLE Logistics Spectrum Magazine, 38:4, pp. 4-9, Oct - Dec. 2004.

[4] K. W. Tobin, J. D. Muhs, “Algorithm for a novel fiber-optic weigh-in-motion sensor system," ORNL/TM 2003-538 (Oak Ridge National Laboratory, Oak Ridge, TN) 2003.

[5] J. D. Muhs, J. K. Jordan, K. W. Tobin, and J. V. LaForge "Apparatus for weighing and identifying characteristics of a moving vehicle,” US Patent \#5,260,520 (November 9, 1993).

[6] D. L. Beshears, G. J. Capps, J. K. Jordan, J. V. LaForge, J. D. Muhs, R. N. Nodine, M. B. Scudiere, and C. P. White, "System and method for accurately weighing and characterizing moving vehicles," US Patent \#5,959,259 (September 28, 1999).

[7] D. L. Beshears, G. J. Capps, J. K. Jordan, J. V. LaForge, J. D. Muhs, R. N. Nodine, M. B. Scudiere, and C. P. White, "System and methods for accurately weighing and characterizing moving vehicles," US Patent \#5,998,741 (December 7, 1999).

[8] J. D. Muhs, M. B. Scudiere, and J. K. Jordan, "Method and apparatus for converting static in-ground vehicle scales into weigh-in-motion systems,” US Patent \#6,459,050 (October 1, 2002).

[9] D. L. Beshears, S.G. Batsell, R. K. Abercrombie, M. B. Scudiere, and C. P. White, "System and method for identifying, validating, and characterizing moving or stationary vehicles and cargo," US Patent Application \#998305 (24 November 2004).

[10] R. K. Abercrombie, F. T. Sheldon, R. G. Schlicher, and K. M. Daley, "Development of the Joint Weigh-In-Motion (WIM) and Measurement Reach Back Capability (WIM-RBC) - The Configuration and Data Management Tool for Validation, Verification, Testing and Certification Activities," Logistics Spectrum, Volume 38, Issue 4, 2004 p. 4-9.

[11] R. K. Abercrombie, F. T. Sheldon, R. G. Schlicher, and K. M. Daley, "Development of the Joint Weigh-In-Motion (WIM) and Measurement Reach Back Capability (WIM-RBC)," 40th Annual International Logistics Conference 2005, Logistics: Product and Process for Capacity, Orlando, Florida 08/16/2005.

[12] "Weigh-In-Motion (WIM) Generation II," U.S. Army Deployment Process Modernization Office (DPMO) Quarterly Army Division Transportation Officer (DTO) \& Mobility Officer (MO) Newsletter, Volume 1, Issue 1, 05/20/2005 p.5. 
[13] R. K. Abercrombie "Next Generation Weigh-In-Motion (WIM): Enhancing Weighing and Measuring of Military Vehicles/Cargo," Institute for Defense and Government Advancement 3rd Annual Meeting, Arlington, VA USA, 03/1/2005.

[14] R. K. Abercrombie "Weigh-in-Motion (WIM) Research and Development Activities at ORNL," International Conference on Weigh-in-Motion, Taipei, Taiwan, 02/21/2005.

[15] R. K. Abercrombie, D. L. Beshears, M. B. Scudiere, J. E. Coats, Jr., F. T. Sheldon, C. Brumbaugh, E. Hart, and R. McKay, "Weigh-In-Motion Research and Development Activities at the Oak Ridge National Laboratory," Fourth International Conference on Weigh In Motion, Taipei, Taiwan, National Science Council, National Taiwan University Publications (ISBN 986-00-0417-X), 2005 pp.139-149.

[16] J. E. Coats, Jr., R. K. Abercrombie, D. L. Beshears, and R. B. Honea, "Weigh-In-Motion Technology for Military Operations: Developing a Portable, Safe, and Accurate System," TR News - Transportation Research Board of the National Academies, vol.231, March-April 2004 pp.16-18.

[17] R. K. Abercrombie, J. E. Coats, Jr., and R. B. Honea, "Weigh-In-Motion (WIM) Technology for InTheater Applications," 83rd Annual Meeting of Transportation Research Board, Washington, DC USA, 01/14/2004.

[18] S. A. Phillips, and R. K. Abercrombie, "Weigh In Motion (WIM) With Rational Rose," Used for fulfillment of RAMS requirement, Oak Ridge, TN USA, 08-08-2003.

[19] "Specifications, Tolerances, and Other Technical Requirements for Weighing and Measuring Devices," NIST Handbook 44, 2006 Edition, U.S. Department of Commerce, p. 2-39. 
APPENDIX A. DEFINITIONS 



\section{APPENDIX A. DEFINITIONS}

A.1 Operationalizing converts a laboratory process (e.g., weight measurements) into a device for field use in a fashion that is repeatable, scalable, and systematic. Specifically, the WIM system has progressed through three development stages: (1) a prototype, for which performance measures cannot be determined easily; (2) an operational device with an infrastructure for easy measurements that are repeatable and accurate; and (3) deployment, including training, certification, and reachback (expert help for problem resolution).

A.2 Sample standard deviation $(\sigma)$ measures the statistical variability in a set of $n$ independent and identically distributed measurements $\left(x_{i}\right)$ of some observable, as the typical distance of the set $\left\{x_{i}\right\}$ from the mean $(\mu)$ :

$$
\mu=\sum_{i=1}^{n} x_{i} / n \text {, and } \sigma^{2}=\sum_{i=1}^{n}\left(x_{i}-\mu\right)^{2} /(n-1) .
$$

Chebyshev's inequality states that most measurements occur close to the mean value. For example, no more than $1 / 4$ of the measurements occur $\geq 2$ standard deviations from the mean, $\leq 1 / 9$ are $\geq 3$ standard deviations away from the mean, $\leq 1 / 16$ are $\geq 4$ standard deviations away from the mean, and so on. In general, the fraction $(f)$ of measurements more than $k$ standard deviations from the mean is: $f \leq 1 / k^{2}$ for $k>1$.

A.3 Precision describes random variability in measurements about the mean. Based on the above definitions, an estimate of precision (percent error, $e$ ) is $e=100 \sigma / \mu$. Standard deviation and precision measure the degree by which additional measurements yield the same or similar results.

A.4 Bias is a non-random or systematic difference between measurements and the true value.

A.5 Accuracy is conformity of a measurement to its actual (true) value. A perfectly accurate measurement has zero bias and zero error. Inaccuracy may arise from either bias or imprecision, or both; see Figure A-1 (The tick mark on the abscissa identifies the actual (true) value).

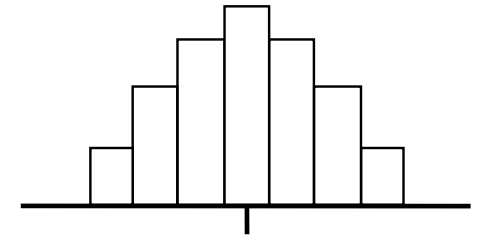

Histogram A

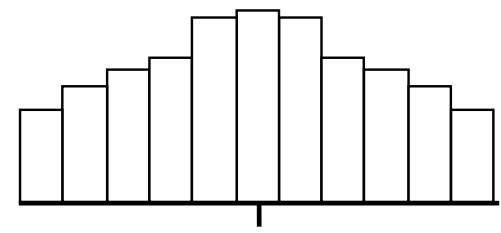

Histogram C

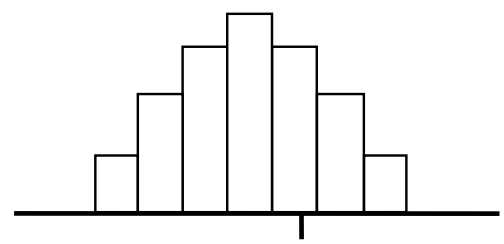

Histogram B

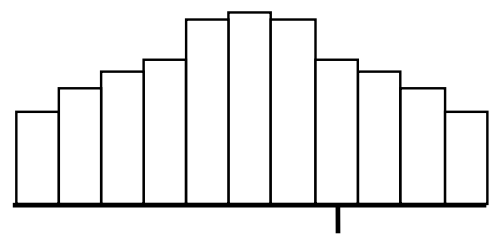

Histogram D

\begin{tabular}{|l|c|c|}
\hline & Unbiased & Biased \\
\hline Less Error (More Precise) & A & B \\
\hline More Error (Less Precise) & C & D \\
\hline
\end{tabular}

Figure A-1. A histographic representation shows the accuracy and bias in a set of measurements. 
A.6 Total vehicle weight $(W)$ is the sum of the weights $\left(w_{i}\right)$ of the individual axles, namely $W=\Sigma_{i} w_{i}$, where the summation $\left(\Sigma_{\mathrm{i}}\right)$ is over all of the individual axle weights.

A.7 Center of Balance (CB) is the position along the vehicle length (starting from the front bumper) where the entire vehicle weight can be balanced: $\mathrm{CB}=\Sigma_{\mathrm{i}} w_{i} L_{i} / W$. Here, $L_{i}$ is the distance of the $\mathrm{i}$-th axle from the front bumper, and the summation $\left(\Sigma_{\mathrm{i}}\right)$ is over all of the axles.

\section{A.8 Discussion}

Statistical analyses for this report used the statistical worksheet functions in Microsoft Excel. Data from the WIM system is processed into a tab-delimited text format, which was then imported into an Excel spreadsheet. The average (Excel worksheet function, "average”) and standard deviation (Excel worksheet function, "stdev") of the multiple measurements from each vehicle/pad combination was calculated for the following measurements: total vehicle weight, axle weights, and center of balance. The Excel worksheet functions ("average" and "stdev") are based on the formulas for average $(\mu)$ and standard deviation $(\sigma)$ in Section A.2. These values were then used to calculate the percent error $(e)$ for each vehicle-pad combination, according to the formula in Section A.3. Table A.1 shows sample data for an illustrative example of ten independent weight values.

Table A-1. Sample data for analysis of total vehicle weight

\begin{tabular}{|l|l|}
\hline Sample & Weight (pounds) \\
\hline 1 & 5808 \\
\hline 2 & 5712 \\
\hline 3 & 5761 \\
\hline 4 & 5770 \\
\hline 5 & 5789 \\
\hline 6 & 5791 \\
\hline 7 & 5815 \\
\hline 8 & 5809 \\
\hline 9 & 5768 \\
\hline 10 & 5794 \\
\hline
\end{tabular}

The average of these ten measurements is 5781.7 pounds. The sample standard deviation for these ten measurements is 30.6 pounds. The error is $100 \% *(30.638 / 5781.7)=0.53 \%$ for the ten measurements from this vehicle-pad combination. This analysis is repeated for each 2-, 4-, and 6-pad vehicle-pad combination. 
APPENDIX B. DETAILED RESULTS FROM VEHICLE TESTS AT NTRC 



\section{APPENDIX B. DETAILED RESULTS FROM VEHICLE TESTS AT NTRC DETAILED}

This appendix describes measurements of total vehicle weight and single-axle weight at the NTRC (Knoxville, Tennessee) on May 10-12, 2005, via three methods: (1) commercial in-ground static scale, (2) WIM in the dynamic mode, and (3) WIM in the stop-and-go mode. WIM measurements used a 6-pad prototype. Each passenger or light-duty commercial vehicle configuration (Table 1 in Section 3.1) was weighed under the same time-sequential protocol (Table 2 in Section 3.1). Table B-1 shows percent error in weight measurements from the in-ground static-scale and WIM. Table B-2 shows additional details about the in-ground scale measurement error by vehicle for total and single-axle weights. Figure B-1 shows percent error for in-ground, static scale measurements of the vehicles. We summarize these results as follows: (1) the in-ground static scale has small error for total vehicle weight, and acceptable error in single-axle weight; (2) WIM measurements in stop-and-go mode meet the Army requirements ( $\leq 1 \%$ error) for both total and axle weights; and (3) WIM measurements in the dynamic mode meet the Army requirements ( $\leq 1 \%$ error) for both total and axle weights via the 6-pad system, although a faster vehicle speed produces more variation (greater error) than slow speed.

Table B-1. Percent error from In-Ground Static Scale and WIM

\begin{tabular}{|l|l|l|}
\hline \multirow{2}{*}{$\begin{array}{l}\text { Measurement } \\
\text { Method }\end{array}$} & \multicolumn{2}{|l|}{ Percent Error } \\
\cline { 2 - 3 } & Total & $\begin{array}{l}\text { Single } \\
\text {-Axle }\end{array}$ \\
\hline In-Ground Static Scale & 0.01 & 0.25 \\
\hline WIM Stop-and-Go & 0.48 & 0.56 \\
\hline WIM Dynamic: Slow (<7 MPH), 2-Pads & 0.47 & 0.51 \\
\hline WIM Dynamic: Slow (<7 MPH), 4-Pads & 0.28 & 0.33 \\
\hline WIM Dynamic: Slow (<7 MPH), 6-Pads & 0.28 & 0.31 \\
\hline $\begin{array}{l}\text { WIM Dynamic: Fast (7-10 MPH), 2- } \\
\text { Pads }\end{array}$ & 1.14 & 1.60 \\
\hline $\begin{array}{l}\text { WIM Dynamic: Fast (7-10 MPH), 4- } \\
\text { Pads }\end{array}$ & 0.72 & 1.24 \\
\hline $\begin{array}{l}\text { WIM Dynamic: Fast (7-10 MPH), 6- } \\
\text { Pads }\end{array}$ & 0.22 & 0.70 \\
\hline
\end{tabular}

Table B-2. Percent error in weights from In-Ground Static Scale by vehicle type

\begin{tabular}{|l|c|c|c|c|}
\hline \multicolumn{1}{|c|}{ Vehicle } & Total & Axle 1 & Axle 2 & Axle 3 \\
\hline S-10 Loaded (Back-Left Corner) & 0 & 0.39 & 0 & - \\
\hline F-250 & 0 & 0.18 & 0 & - \\
\hline F-250 Loaded (Back-Left Corner) & 0 & 0.19 & 0.88 & - \\
\hline F-250 Loaded (Back-Center) & 0 & 0.19 & 0.36 & - \\
\hline F-250 Loaded (Left-Center) & 0 & 0.36 & 0.75 & - \\
\hline H2 Loaded & 0 & 0 & 0 & - \\
\hline H2 with Trailer & 0.08 & 0 & 0.11 & 0.35 \\
\hline Average Error (also in Table B-1) & $\mathbf{0 . 0 1}$ & & $\mathbf{0 . 2 5}$ \\
\hline
\end{tabular}




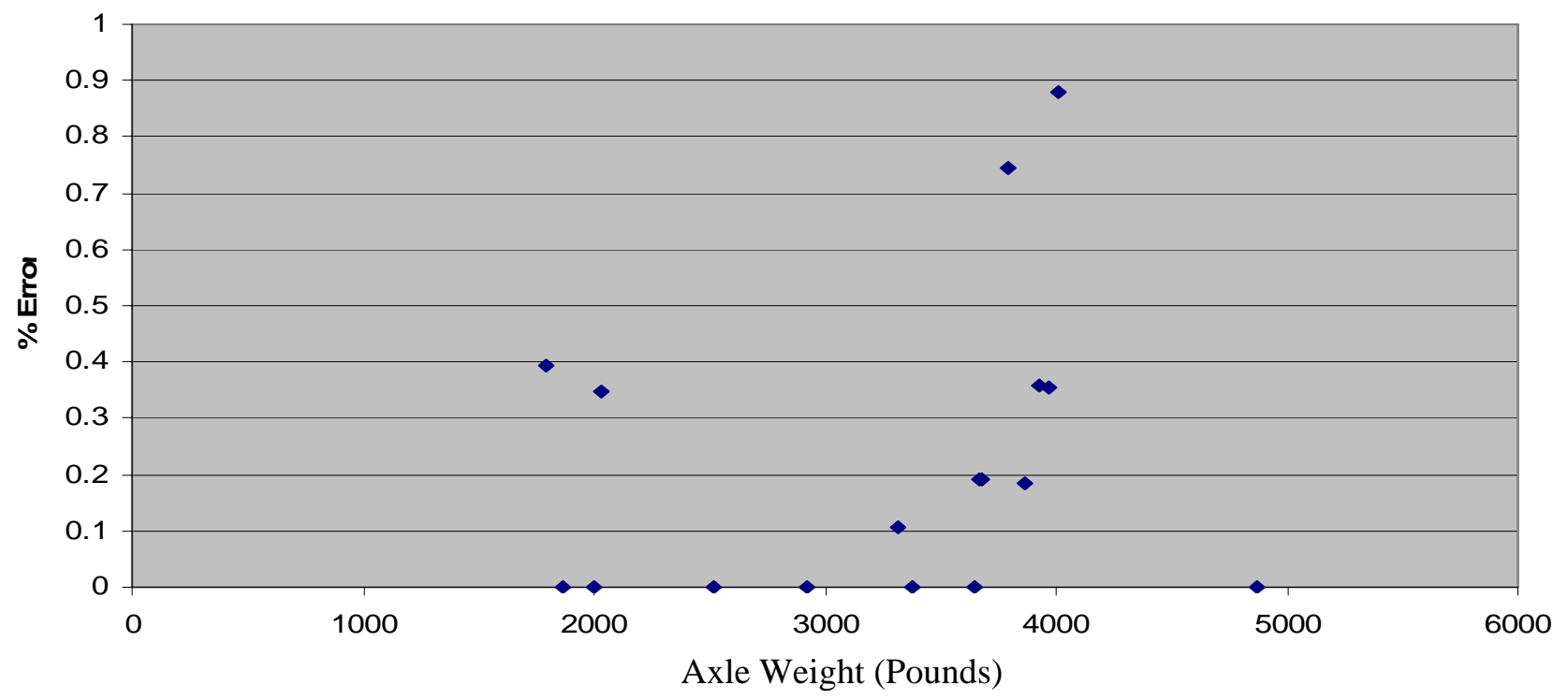

Figure B-1. Percent error in axle weights of passenger and light-duty vehicles on In-Ground Static Scale. 
APPENDIX C. DETAILED RESULTS FROM FT. BRAGG / POPE AFB 



\section{APPENDIX C. DETAILED RESULTS FROM FT. BRAGG / POPE AFB}

This appendix summarizes measurements of total and single-axle weights at Ft. Bragg/Pope AFB (North Carolina) on May 24-26, 2005, via: (1) commercial in-ground static scale, (2) WIM in the dynamic mode, and (3) WIM in the stop-and-go mode. WIM measurements were done using a 6-pad prototype. These tests facilitated the development of a methodology for evaluating the performance of the first-article WIM and provided a performance benchmark of the first-article WIM system. Each military vehicle configuration (Table 3 in Section 3.2) was weighed under the time-sequential protocol in Table 2 in Section 3.1. Table C-1 shows percent error in weight measurements from the in-ground static-scale and WIM. Tables C-2 and C-3 show additional details about results in Table C-1, in terms of error in total weight and in axle weight (respectively) by vehicle. Average error in Table C-3 was determined without the PLS-Axle-5 values, which we deem to be outliers (and hence are shown in parentheses). Figure C- 1 shows percent error versus singleaxle weight from the in-ground scale; the error (up to 5\%) is worse for axle weights above 7,500 pounds. Figure C-2 shows the percent error versus single-axle weight from the WIM dynamic measurement; the error decreases with increasing single-axle weight. We summarize these results as follows: (1) the in-ground static scale has small error for total vehicle weight, but has excessive error $(>1 \%)$ for single-axle weight (part of the vehicle off the scale, and the part of the vehicle on the scale); (2) WIM stop-and-go measurements meet the Army requirements ( $\leq 1 \%$ error) for total and single-axle weights; and (3) WIM measurements in the dynamic mode meet the Army requirements ( $\leq 1 \%$ error) for both total and single-axle weights via the 4- and 6-pad system at slow speed. Faster-moving vehicles also pose a greater safety hazard. Thus, we recommend a slowspeed WIM dynamical measurement for acceptable error.

Table C-1. Percent error from In-Ground Static Scale and WIM

\begin{tabular}{|l|l|l|}
\hline Measurement Method & \multicolumn{2}{|c|}{$\begin{array}{c}\text { Percent } \\
\text { Error }\end{array}$} \\
\hline & Total & $\begin{array}{l}\text { Single } \\
\text {-Axle }\end{array}$ \\
\hline In-Ground Static Scale & 0.07 & 1.47 \\
\hline WIM Stop-and-Go & 0.62 & 0.67 \\
\hline WIM Dynamic: Slow (<7 MPH), 2-Pads & 0.54 & 1.02 \\
\hline WIM Dynamic: Slow (<7 MPH), 4-Pads & 0.46 & 0.67 \\
\hline WIM Dynamic: Slow (<7 MPH), 6-Pads & 0.46 & 0.62 \\
\hline WIM Dynamic: Fast (7-10 MPH), 2-Pads & 2.25 & 3.40 \\
\hline WIM Dynamic: Fast (7-10 MPH), 4-Pads & 1.56 & 2.76 \\
\hline WIM Dynamic: Fast (7-10 MPH), 6-Pads & 0.99 & 2.12 \\
\hline
\end{tabular}


Table C-2. Percent error in total weight: WIM stop-and-go mode versus In-ground Static Scale

\begin{tabular}{|l|c|c|c|}
\hline \multicolumn{1}{|c|}{ Vehicle } & $\begin{array}{c}\text { WIM Stop-and-Go } \\
\text { Mode }\end{array}$ & $\begin{array}{c}\text { In-ground Scale } \\
\text { Before WIM }\end{array}$ & $\begin{array}{c}\text { In-ground Scale } \\
\text { After WIM }\end{array}$ \\
\hline HUMVEE & 0.48 & 0.18 & 0.00 \\
\hline HUMVEE with Trailer & 0.55 & 0.10 & 0.19 \\
\hline FMTV & 0.65 & 0.00 & 0.08 \\
\hline FMTV loaded & 0.60 & NA & NA \\
\hline HEMTT & 0.73 & 0.04 & 0.04 \\
\hline HEMTT loaded & 1.09 & 0.06 & 0.02 \\
\hline PLS & 0.22 & 0.05 & 0.03 \\
\hline Average Error & $\mathbf{0 . 6 2}$ & & $\mathbf{0 . 0 7}$ \\
\hline
\end{tabular}

Table C-3. Percent error in axle weights: WIM stop-and-go mode versus In-ground Static Scale

\begin{tabular}{|l|c|c|c|c|}
\hline \multicolumn{1}{|c|}{ Vehicle } & Axle & WIM Stop-and-Go & $\begin{array}{c}\text { Fixed In-ground } \\
\text { Scale Before WIM }\end{array}$ & $\begin{array}{c}\text { Fixed In-ground } \\
\text { Scale After WIM }\end{array}$ \\
\hline HUMVEE & Axle 1 & 0.75 & 0.65 & 0.33 \\
\hline HUMVEE & Axle 2 & 0.48 & 0.42 & 0.00 \\
\hline HUMVEE with Trailer & Axle 1 & 0.80 & 1.28 & 0.72 \\
\hline HUMVEE with Trailer & Axle 2 & 0.87 & 0.80 & 0.57 \\
\hline HUMVEE with Trailer & Axle 3 & 0.18 & 0.31 & 0.31 \\
\hline FMTV & Axle 1 & 0.55 & 0.50 & 0.37 \\
\hline FMTV & Axle 2 & 1.04 & 0.21 & 0.43 \\
\hline FMTV loaded (day 1) & Axle 1 & 0.15 & 0.00 & NA \\
\hline FMTV loaded (day 1) & Axle 2 & 0.80 & 0.10 & NA \\
\hline FMTV loaded (day 2) & Axle 1 & 0.56 & 0.08 & NA \\
\hline FMTV loaded (day 2) & Axle 2 & 0.46 & 0.18 & 3.14 \\
\hline HEMTT & Axle 1 & 0.42 & 3.40 & 1.51 \\
\hline HEMTT & Axle 2 & 0.96 & 1.47 & 2.38 \\
\hline HEMTT & Axle 3 & 0.84 & 1.16 & 2.58 \\
\hline HEMTT & Axle 4 & 1.09 & 3.56 & 0.85 \\
\hline HEMTT loaded & Axle 1 & 0.40 & 2.58 & 0.75 \\
\hline HEMTT loaded & Axle 2 & 1.23 & 1.12 & 2.09 \\
\hline HEMTT loaded & Axle 3 & 1.17 & 1.19 & 3.84 \\
\hline HEMTT loaded & Axle 4 & 1.60 & 2.38 & 1.30 \\
\hline PLS & Axle 1 & 0.13 & 3.86 & 1.47 \\
\hline PLS & Axle 2 & 0.15 & 0.91 & 3.33 \\
\hline PLS & Axle 3 & 0.50 & 0.35 & $(13.06)$ \\
\hline PLS & Axle 4 & 0.19 & & $\mathbf{1 . 4 7}$ \\
\hline PLS & Axle 5 & 0.69 & $\mathbf{0 . 6 7}$ & \\
\hline Average Error & & & & \\
\hline
\end{tabular}




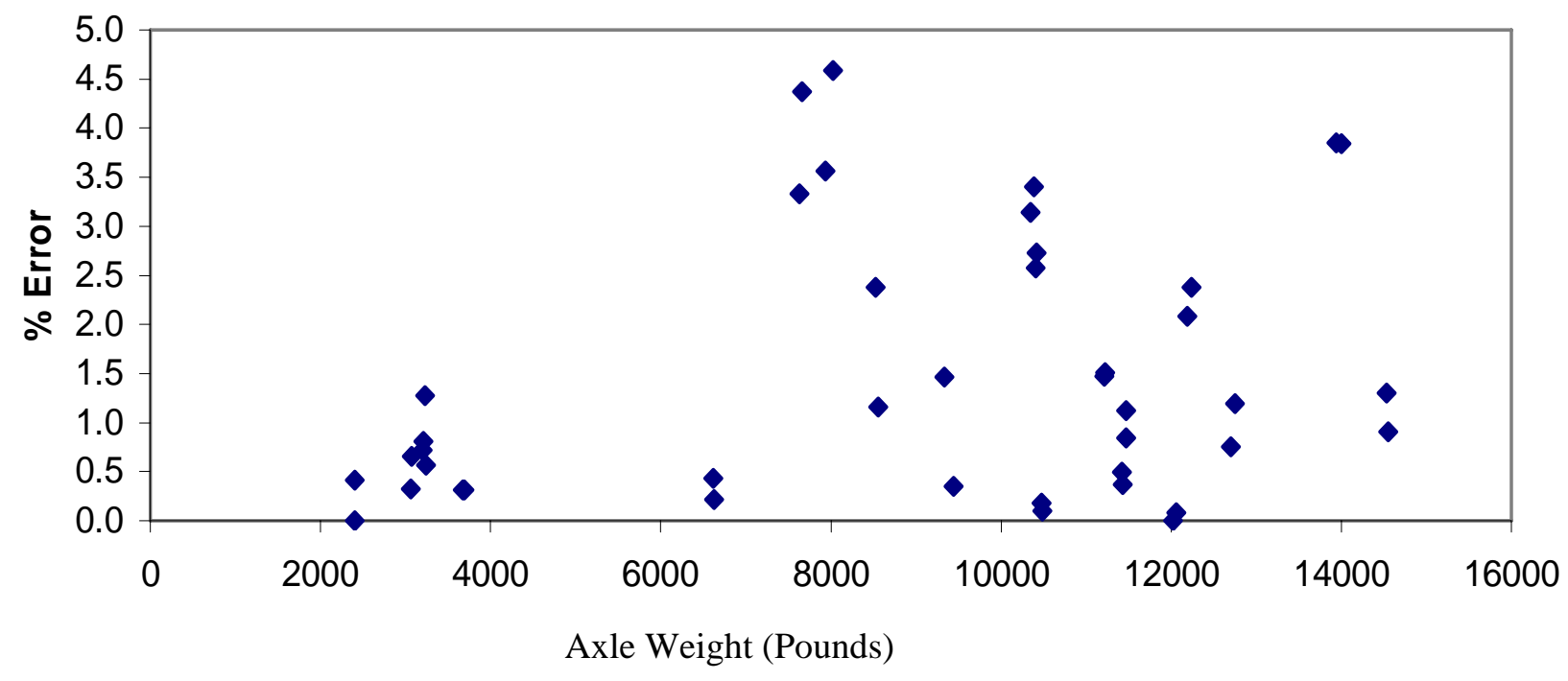

Figure C-1. Percent error versus single-axle weight from the In-Ground Static Scale.

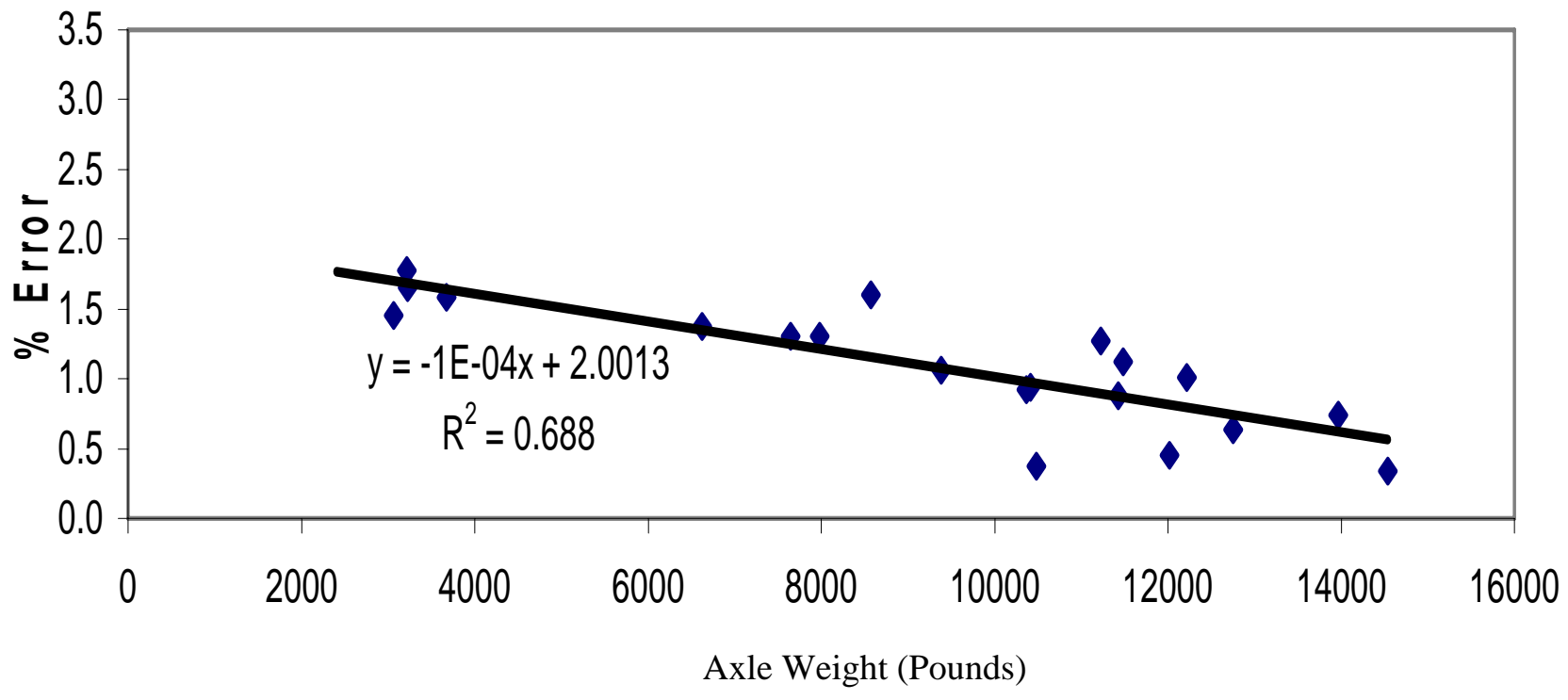

Figure C-2. Percent error versus single-axle weight from the WIM dynamic mode. 

APPENDIX D. WIM EQUIPMENT AND MEASUREMENT PROCEDURES 



\section{APPENDIX D. WIM EQUIPMENT AND MEASUREMENT PROCEDURES}

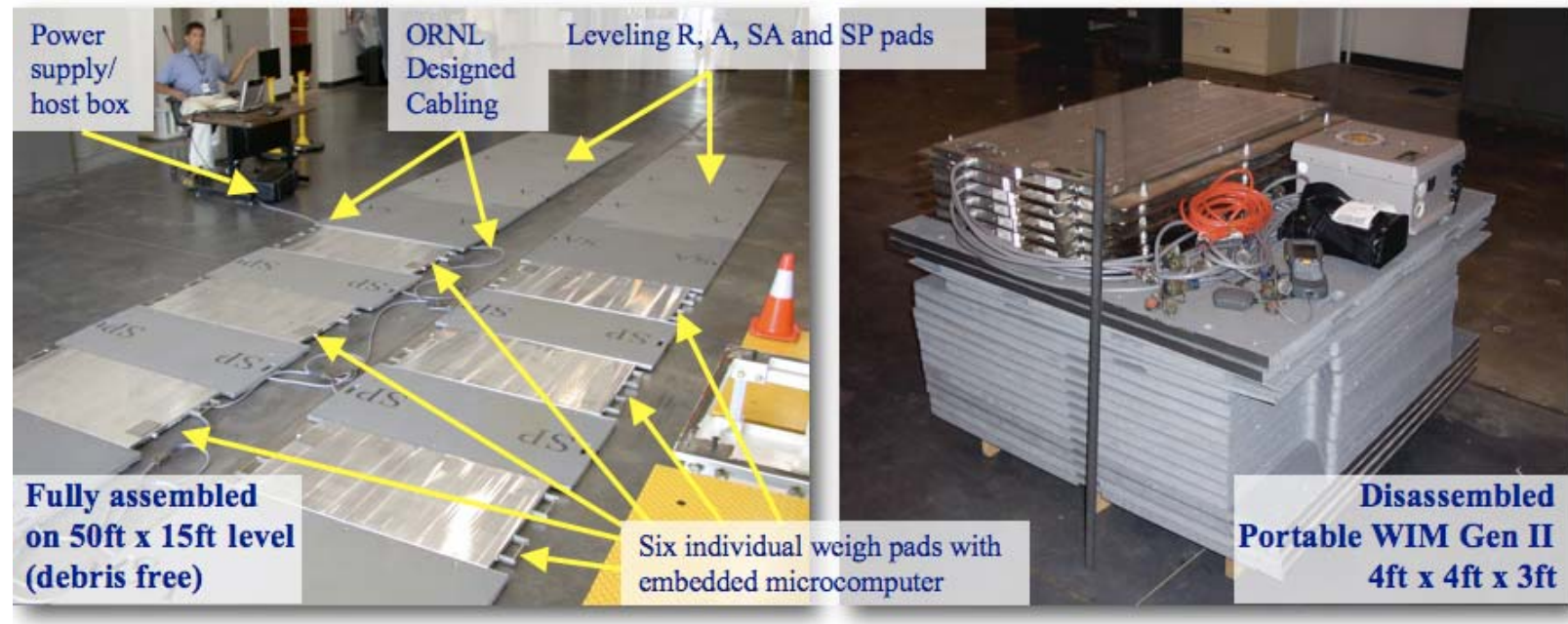

Figure D-1. WIM Gen II system hardware package.

Figure D-1 shows the WIM hardware (host computer, weigh pads, spacer pads, approach pads, and connector

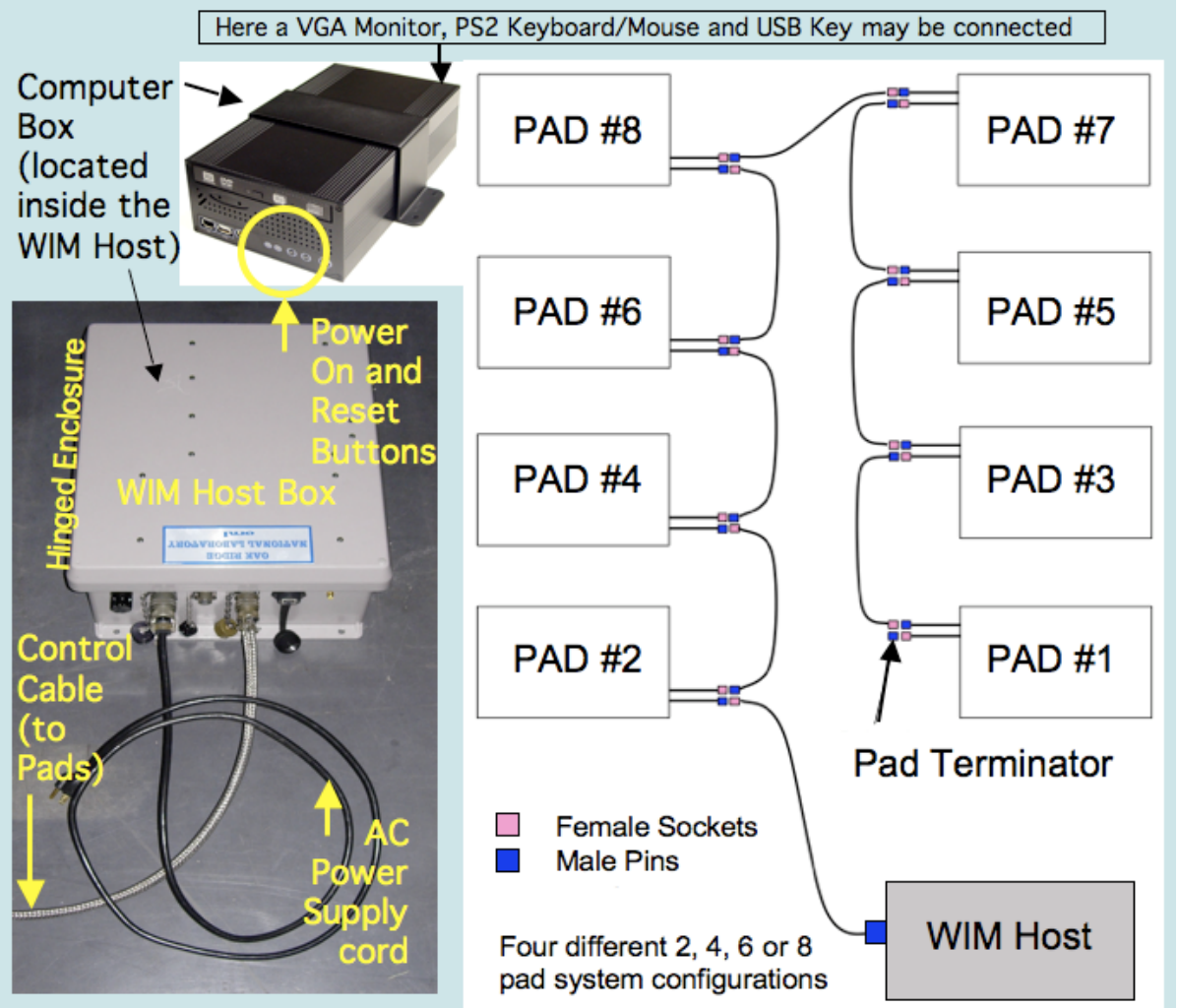

Figure D-2. WIM Gen II cabling diagram with host box and computer. cables) package in both the fully assembled and fully (stacked) disassembled configurations. The system can be quickly assembled from the stacked configuration (see Fig. D-3). The assembled configuration requires a level smooth surface that is approximately fifty feet long by fifteen feet wide (free of debris such as loose gravel, sand and trash) that will provide sufficient maneuvering room for all vehicles to be weighed. The WIM Host box contains the Windows based computer which is connected to the weigh pads (up to 8 pairs) as shown in Figure D-2

Additional components include the WIM software: a handheld device that runs Windows Mobile 2005 or Microsoft Pocket PC (e.g. Symbol 8146), WIM Client software, communications via the IEEE wireless 801.11b/g protocol, and Microsoft ActiveSync.

The WIM System forms a stand-alone network. An additional outside link is possible when the WIM-Client Pocket-PC cradles or when it connects to an outside computer (e.g. a computer at a Base Installation). 


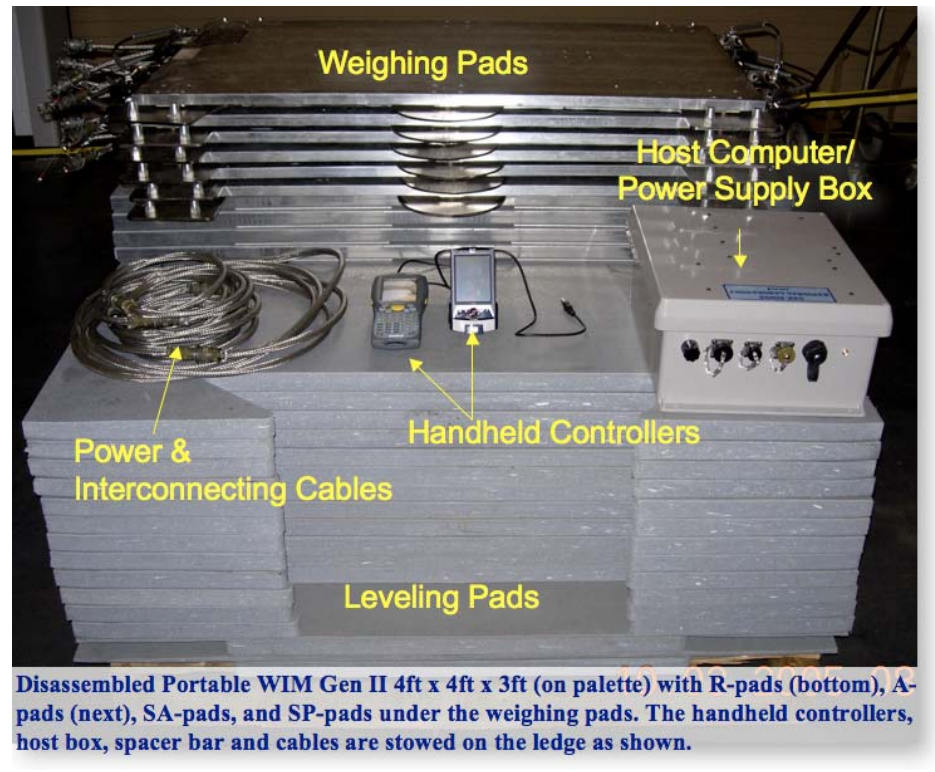

Figure D-3. WIM properly stacked for quick assembly.
Bluetooth is not used. Network communications use the $802.11 \mathrm{~b} / \mathrm{g}$ protocol (Wi-Fi) for the WIM-Host and WIMClient(s). The Controller Area Network (CAN) is an ISO 111898-1, multicast, shared serial bus for robustly connecting electronic components in noisy environments; see http://www. Kvaser.com/can/protocol/index.htm . Data synchronization (Microsoft ActiveSync) between the WIM-client and a host computer is via USB connections.

Weight data from the pads is collected, processed and stored by the WIM Host, which sends the weight data to the WIM Client. The weight data is integrated by the WIM Client with additional information about the vehicle in a variety of data formats for military systems (e.g., TC-AIMS II, AALPS, and ICODES). The WIM Client also transmits the vehicle weight and measurement data securely to the Reachback Capability (RBC). Authorized users can then access and retrieve current and/or historical data for analysis via the RBC.

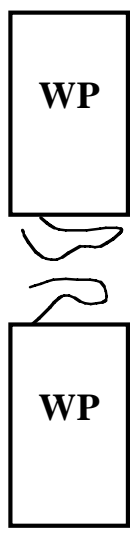

Figure D-4. Placement of first two WIM measurement pads (WP).
The disassembled WIM system stacks into a 4' x 4' x 3' space for portability, easy shipping, and assembly in about 20 minutes by a two-person team. Assembly involves five steps: (1) site selection and preparation, (2) alignment of the weighing pads, (3) installation of the approach- and ramp-pads, (4) connection of the cabling to the weighing pads, and (5) connection of the power cables to the WIM host. An appropriate site should have a flat, smooth surface approximately 50 feet (15.2 $\mathrm{m})$ long and at least 15 feet $(4.6 \mathrm{~m})$ wide. This area must be swept clean to remove debris (e.g., sand, loose gravel, trash). Assembly begins by placing two weigh pads (WP) in the center of the assembly with the pigtail cables facing inward. The spacer bar is used to set the proper separation (33 inches $/ 84 \mathrm{~cm}$ ) between the inside edges of the weigh pads. This separation provides the optimum center-tocenter spacing of the pads for the purpose of weighing a majority of military vehicles. See Figure D-4.

Then, the spacer pads (SP) are placed at each end of these two weighing pads, so that the locking pins in the weighing pad fit into the corresponding holes at each end of the spacer pads. See

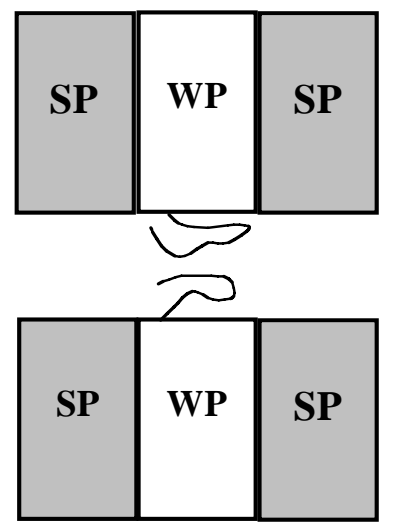

Figure D-5. Placement of spacer pads (SP).

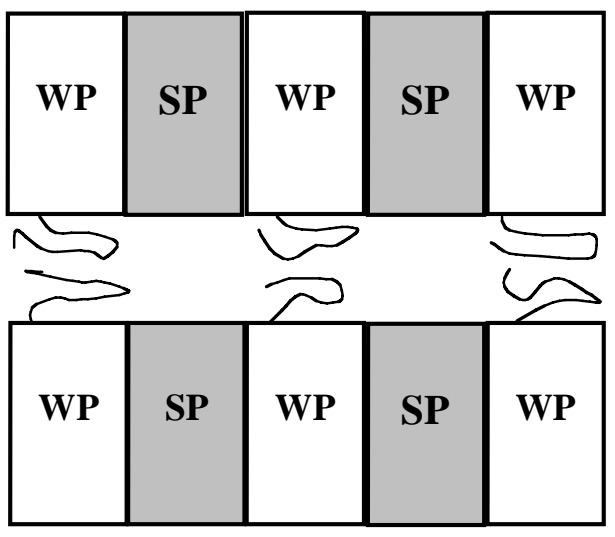

Figure D-6. Placement of next four weigh pads. 
Figure D-5.

Next, the four remaining weigh pads are placed at the ends of the spacer pads, so that the locking pins in the weighing pad fit into the corresponding holes at each end of the spacer pads. See Figure D-6. The result is two parallel sequences of: WP, SP, WP, SP, WP.

Subsequently, approach pads (AP) and spacer-approach (SA) pads are installed on each end of the assemblies, as shown in Figure D-7. Each assembly now has the sequence: AP, AP, SA, WP, SP, WP, SP, WP, SA, AP, AP.

The main power/signal cable should be routed through the groove in the bottom of the spacer-approach pad that is nearest the host computer. The weigh pads are then daisy-chained together using connector cables, and the main power/signal cable is connected to the host computer. The remaining pigtail connector in the daisychain should remain terminated with its protective cap. Completion of the assembly involves connection of the power cord.

The WIM procedure to weigh vehicles begins by assuring that the software on the Host (Pocket-PC or other handheld device) is running and properly accessing the WIM local-area network. Then, the user must select the method for the WIM weight measurement, as either dynamic mode or stop-and-go mode. WIM dynamic

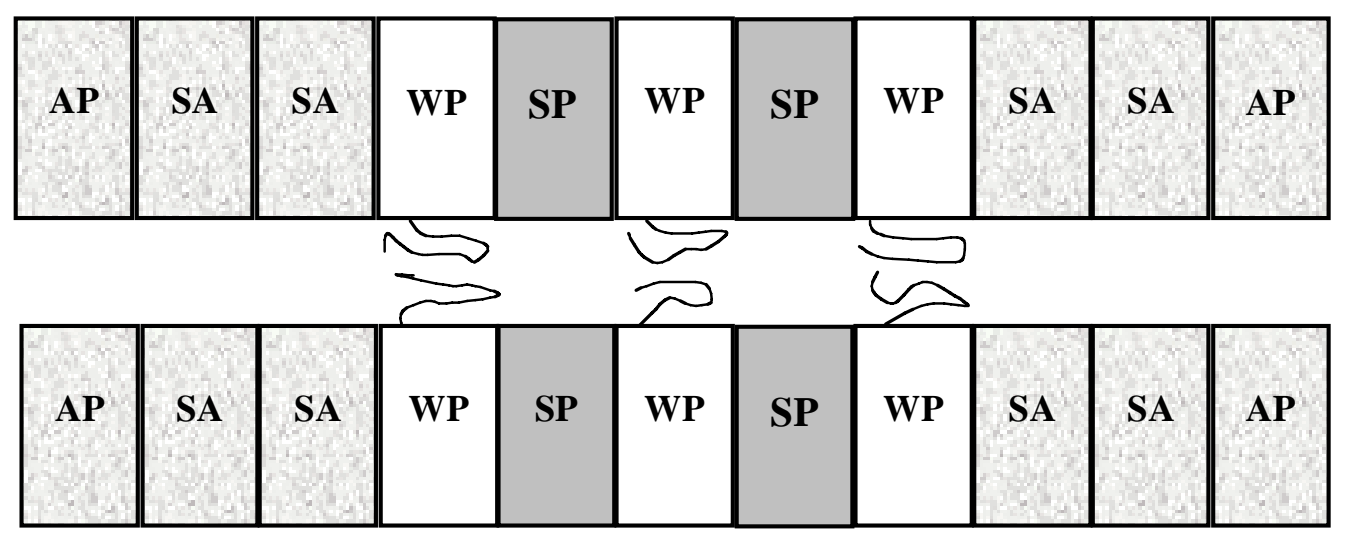

Figure D-7. Placement of approach pads (SA and AP).

measurements involve the vehicle passing over the pads at a constant speed between 3 and 7 mph. WIM stopand-go measurements require the vehicle to approach the pads slowly until the front tires are near the center of the center set of weigh pads, assuring that the entire tire footprint is centered on each pad. The first-axle weight can be accepted after the vehicle's rocking motion stops. This process is repeated for each subsequent axle.

The measurement procedure for an in-ground scale is very different. An accurate total weight requires positioning the vehicle as close to the center of the static scale as possible; the weight is then recorded. Single-axle weights involve positioning only the first axle on the static scale, as close to the center as possible; the first-axle weight (W1) is then recorded. The vehicle is next positioned to have only the first and second axles on the scale (again, as close to the center as possible); the first-plus-second-axle weight (W1 + W2) is then recorded. This process is repeated until all of the axles are weighed (e.g., W1, W2, W3, W4). Subsequently, the weight of the second axle (W2) is obtained from:

$$
\mathrm{W} 2=(\mathrm{W} 2+\mathrm{W} 1)-\mathrm{W} 1 .
$$

The weight of the third axle can be obtained from:

$$
\mathrm{W} 3=(\mathrm{W} 1+\mathrm{W} 2+\mathrm{W} 3)-(\mathrm{W} 1+\mathrm{W} 2) .
$$

Likewise, the weight of the fourth axle is:

$$
\mathrm{W} 4=(\mathrm{W} 1+\mathrm{W} 2+\mathrm{W} 3+\mathrm{W} 4)-(\mathrm{W} 1+\mathrm{W} 2+\mathrm{W} 3) .
$$

The procedure can be repeated for all of the axles on the vehicle. 
The weigh pads are roughly dimensioned as shown in Figure D-8.

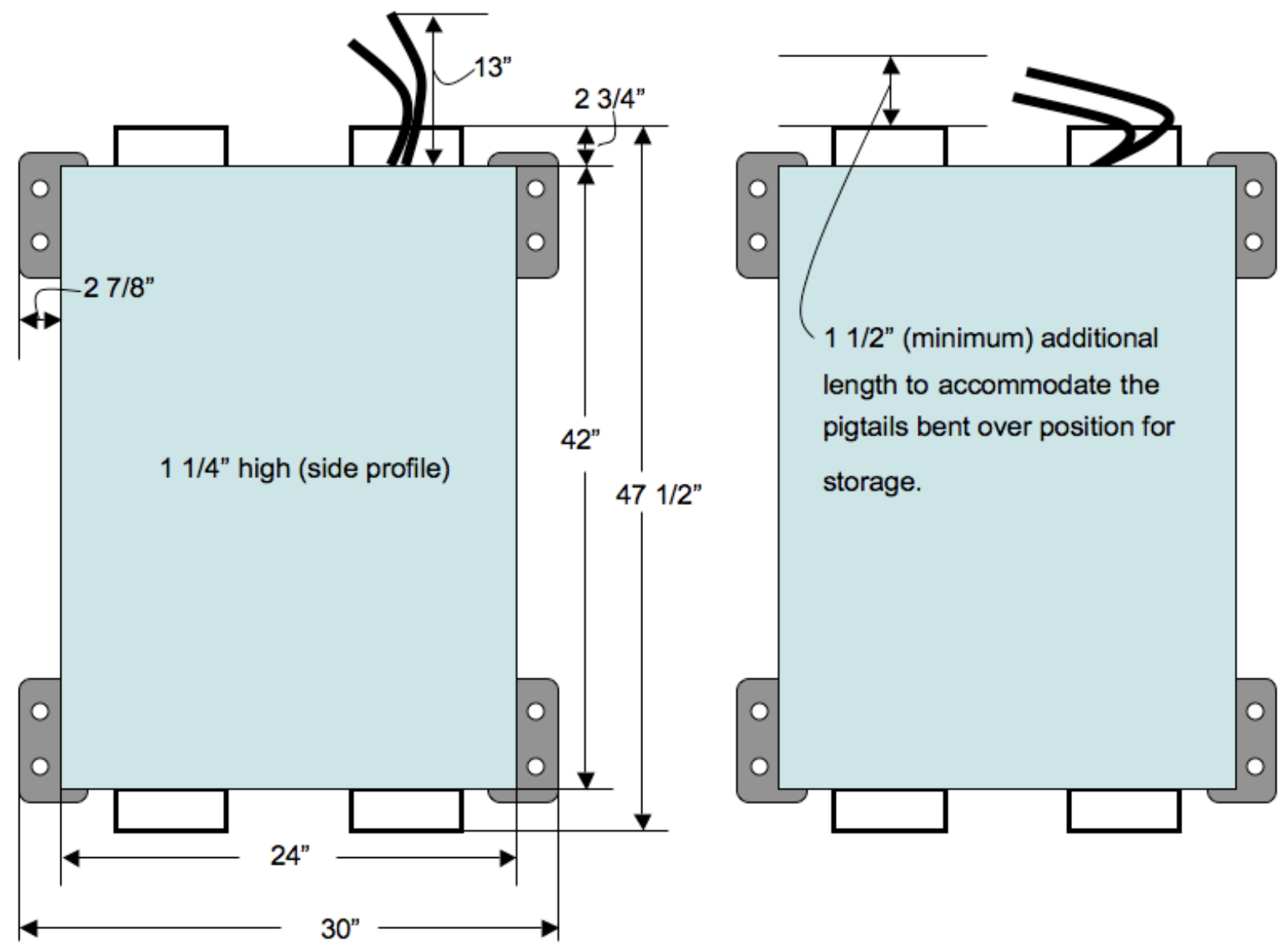

Figure D-8. Rough weigh pad (WP) dimensions. 
APPENDIX E. RECOMMENDATIONS FOR FIELD USE OF WIM 



\section{APPENDIX E. RECOMMENDATIONS FOR FIELD USE OF WIM}

The recommendations from our measurements and analysis to date are as follows.

\section{Ground Preparation}

- The area for layout of the WIM system should have a level approach and exit of 100 feet.

- Before placement of the WIM pads, the road surface should be swept clean of debris, because even small particles below the pads can adversely affect the weight measurements.

- Pads should be placed on level (flat) ground. Ground curvature produces pad rocking during traversal of a tire, affecting not only the pad in question, but also the whole system. We may need to explore a standardized method to determine ground flatness (suitability).

- The pads should be positioned to prevent movement/migration of any kind. We observed pad migration in the direction of travel and sideways during tests at Ft. Bragg/Pope AFB. This migration occurred even though the cement surface was somewhat rough.

- The use of non-skid material between the pads and the road surface may be needed to ameliorate the above non-ideal conditions.

\section{Vehicle Speed}

- Speed changes during vehicle passage over the weighing pads result in adverse effects on the WIM system, including: (1) larger error in the WIM weight measurement, (2) additional rocking motion of the pads (as noted above), and (3) additional sliding motion (as noted above).

- We recommend a constant speed of not more than $5 \mathrm{mph}$ for WIM dynamic-mode measurements to reduce percent error. Faster-moving vehicles also pose a larger safety hazard. Some vehicles are equipped with active suspensions, for which WIM compensation is not possible. Consequently, such vehicles should be weighed under conditions that remove such effects (e.g., fully extended or fully retracted). Moreover, the vehicle speed should be held as constant as possible during the weighing process. 



\section{INTERNAL DISTRIBUTION}

1. R. K. Abercrombie

2. D. J. Adams

3. D. L. Beshears

4. G. J. Capps

5. J. E. Coats, Jr.

6. R. M. Davis

7. G. A. Fisher, Jr.

8. E. C. Fox

9. W.H. Gray

10. L. M. Hively

11. D. K. Jackson

12. S. R. McNeany

13. J. D. Muhs
14. G. D. Richardson

15. B. G. Schlicher

16. M. B. Scudiere

17. F. T. Sheldon

18. D. B. Smith

19. J. P. Trien

20. C. P. White

21. B. A. Worley

22. Central Research Library

23. ORNL Laboratory Records-RC

24. ORNL Laboratory Records-OSTI

\section{EXTERNAL DISTRIBUTION}

1. James Schmidhammer, 314 Conference Center Bldg, 600 Henley St., Knoxville, TN 37996

2. Jeff Vanvactor, 1836 Bisbee Lane, Knoxville, TN 37931

3. Carolyn Brumbaugh, Logistics Innovation Agency, 5870 21st Street, Bldg 212, Ft. Belvoir, VA 22060

4. Christie McLaughlin, Logistics Innovation Agency, 5870 21st Street, Bldg 212, Ft. Belvoir, VA 22060

5. Robert McKay, Logistics Innovation Agency, 5870 21st Street, Bldg 212, Ft. Belvoir, VA 22060 